\title{
Agents of change
}

\author{
Elizabeth Kay, Editor, EBD
}

\section{$\Lambda$} s I have mentioned before, if you ask a researcher why they do what they do, almost ubiquitously, they will answer that it is because they want to 'make a difference'. This, I believe, is a wonderful sentiment and to be applauded. But 'making a difference' means bringing about change - real and long-lasting change - change, perhaps in society or in healthcare, or maybe even in someone's behaviour. All of us in research - those conducting the primary studies, those who seek meaning from the available evidence by conducting systematic reviews and those who interpret the findings to make them accessible to others - are agents of change. And although it's part of our job to ensure that we are agents of change, it is essential we are agents of change for good and always agents of change which is based on evidence, and not on dogma or belief...or worse...on what we were taught!

Consider for a moment the changes that have occurred over the last two years. Quite apart from the massive shift in our knowledge and understanding of viruses, there have been monumental changes in our behaviours, and indeed, huge alterations in social norms (something that usually takes decades or even millennia!) There has also been a long overdue and sudden recognition of the enormous importance of mental health to population wellbeing. So now we know that, in a crisis, when pushed, we can learn and discover and change at a rate we wouldn't have thought possible. And indeed, we can do things of which we could not even conceive only a couple of years ago.

Just think what dentistry was like in the past and then consider dentistry of the present day. Then, try to envisage dentistry of the future. Definitely, it will be very, very different - because change is inevitable. Indeed, it is one of the very few certainties that we have. And if when you look into that future and you do not like what you see...change it. You can create the change you want to see, through your contribution to evidence. You, the academics, the research community, are among the brightest, the most innovative and the most motivated in the world. You CAN change things for the better...by being courageous and clever. But each of you does have the opportunity to bring about change, maybe in prevention, maybe in restorative techniques; perhaps in periodontal healthcare, or even general health - but you can only bring about change by evidencing the need for it. With evidence as your advocate, you will succeed. You are the future of your chosen

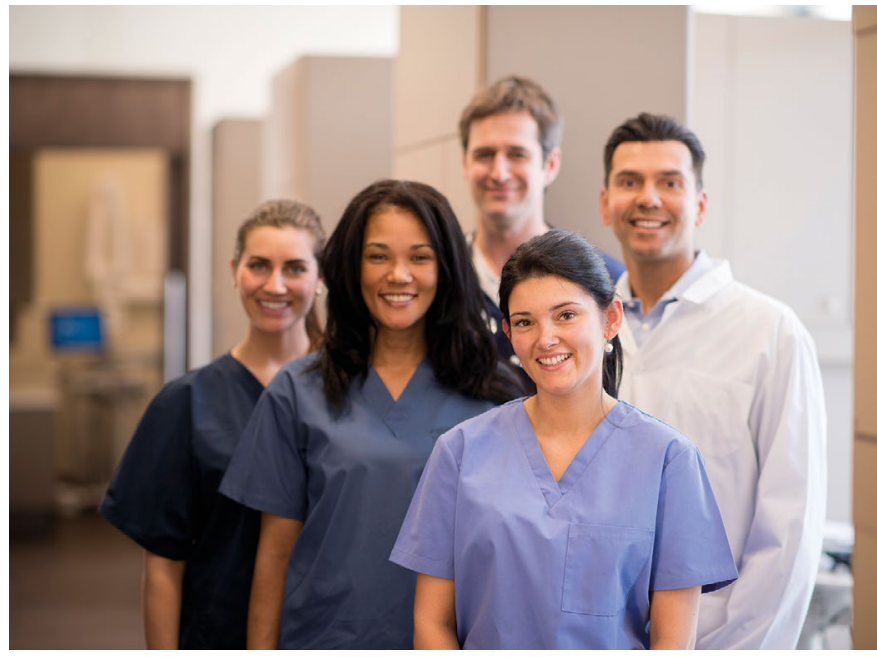
profession. Each one of you can influence the direction dentistry takes. You can alter, in some way, the profession's direction of travel.

And that is what research is about. It seeks truth. It rejects habit. It welcomes new thinking. It challenges the status quo. So to be a great researcher perhaps requires an individual to have a somewhat rebellious spirit and to be a slightly maverick soul. Research needs people who dare to think differently and are happy to open doors to new ways of dealing with things. But of course, saying something original or that some long-utilised technique is ineffective, or that previous thinking was erroneous, will always face opposition. And new ways of thinking, or innovations in the way things are viewed, will always be challenged. But that is why it is important that whatever your line of research, whatever you have discovered or will discover, you must publish and you must not be afraid of the 'establishment' view. For the world to benefit from your work, and recognise your skills and your discoveries, you must publish and lecture and discuss, for that is what brings about change. No matter how much of an 'outsider' or a 'different thinker' you are (and such people probably make the very best researchers), you must make your voice heard. You need to get onto that inside track and sit alongside your decriers until your message is received. This you must do, otherwise things will never change and you, the world's dental researchers, are agents of change for the better - and dentistry needs you.

Just think about the nature and pace of change. What will your professional world look like 35 years from now? Where will dentistry be? Well, the only thing that I can tell you is that the world of dentistry and the world of academia is nothing like the world in which I began my career. Just try for a moment to imagine it...there were no computers, not even in the library of my university! There was no such thing as the internet! And you would have been considered completely crazy if you suggested that a photograph could be taken with a phone! What terrifies me is that the pace of change is getting faster and faster. So the world that you will inhabit when you are 60 will be completely and utterly different from the one you know today - and so will your profession. That is why the research we do today is so important. Think about David $50 \%$ of what is taught in medical and dental schools today will be proven to be wrong within ten years. Consider part of your job to find out which half that is!

Good luck and keep going. Your contribution will have impact and will make the world better.

Evidence-Based Dentistry (2021) 22, 120. https://doi.org/ 10.1038/s41432-021-0232-9 Sackett's famous insight when he told us that 